\title{
A Case of Gastrinoma in a Shih-Tzu Dog
}

\author{
Ushio FUKUSHIMA $^{1)}$, Miyuki SATO ${ }^{1)}$, Shozo OKANO ${ }^{2)}$, Yoshitaka ARAMAKI ${ }^{3)}$, Hiroshi ITO $^{3)}$, Kazuki YOSHIOKA $^{4)}$, \\ Toshifumi OYAMADA ${ }^{5)}$ and Masami UECHI ${ }^{1)}$
}

${ }^{1)}$ Veterinary Teaching Hospital, ${ }^{2)}$ Departments of Small Animal Medicine, ${ }^{3)}$ Veterinary Surgery, ${ }^{4)}$ Veterinary Anatomy and ${ }^{5)}$ Veterinary Pathology, School of Veterinary Medicine and Animal Sciences, Kitasato University, Towada, Aomori 034-8628, Japan

(Received 22 January 2003/Accepted 6 November 2003)

ABSTRACT. A five-year-old male Shih-Tzu dog presented with severe vomiting and weight loss. The clinical signs were successfully improved by an eight-day treatment with an $\mathrm{H}_{2}$-receptor antagonist, gastrointestinal protectant and antibiotics. Ten days later, however, recurrence of vomiting was seen despite continuous medical treatment. Based on clinical signs and the results of various diagno stic tests including CBC, biochemical analysis, contrast radiography, and endoscopy, a duodenal or pancreatic neoplasm was suspected and exploratory laparotomy was conducted. Some swollen pancreatic regions were found, and biopsy of the pancreas indicated the diagnosis of a gastrin-secreting tumor. Consequently, based on a high serum gastrin level as well as clinical signs and immunohistological findings, we diagnosed the disease as canine gastrinoma, a rare tumor of the pancreas.

KEY WORDS: canine, gastrinoma, Zollinger-Ellison syndrome.

J. Vet. Med. Sci. 66(3): 311-313, 2004

Originally described by Zollinger and Ellison and known as the cause of Zollinger and Ellison syndrome in humans [16], gastrinoma is a gastrin-secreting neoplasm of the pancreatic cells. This disease is characterized by a gastrointestinal ulcer and erosion as a consequence of hypersecretion of gastric acid from the parietal cells of the stomach wall stimulated by hypergastrinemia [14]. Because of severe gastrointestinal peptic lesions the main clinical signs of the disease are vomiting, melena, anorexia, and weight loss. Here we report a case of canine gastrinoma, a rare tumor of the pancreas, in contrast to insulinoma a tumor of the pancreas seen more commonly in veterinary medicine [4].

A 5-year-old male Shih-Tzu dog was referred to our hospital with a three-week history of vomiting, anorexia, and weight loss. On physical examination the animal's visible mucosal membranes were found to be pale, and an apical systolic murmur was noticed (left: Levine 3/6, right: Levine 2/6). On microscopic examination of the blood, microfilaria was negative. Complete blood count (CBC) and plasma biochemical analysis showed marked neutrophilia, mild hypokalemia, hypocalcemia, hypoproteinemia, and mildly increased alkaline phosphatase activity (Table 1). Results of an adrenocorticotropic hormone (ACTH) stimulation test were within normal levels. On echocardiography, moderate mitral and tricuspid valve regurgitation were noted. An abdominal X-ray showed some gas retention at multiple sites in the duodenum and ascending colon, together with thickening of the gastroduodenal membrane. A contrast radiographic technique produced films showing an irregular mucosal membrane of the duodenum as well as a thickened wall throughout the small intestine (Fig. 1). No other findings suggesting the presence of a foreign body in the digestive tract or intussusception were obtained from the films. On endoscopy, a small mass as well as mucosal ulceration and erosion were found in the gastric pyloric region. The mass was biopsied and then histologically identified as an adenoma.

The dog was managed with sucralfate $(30 \mathrm{mg} / \mathrm{kg}$, tid), ranitidine hydrochloride $(2 \mathrm{mg} / \mathrm{kg}$, bid), metoclopramide hydrochloride $(0.3 \mathrm{mg} / \mathrm{kg}$, bid), and antibiotics (cefazolin sodium, $20 \mathrm{mg} / \mathrm{kg}$, and orbifloxacin, $5 \mathrm{mg} / \mathrm{kg}$ ), in combination with electrolyte and fluid therapy for the correction of abnormalities caused by vomiting. The clinical signs, vomiting, depression and anorexia, were improved by medication in eight days. Ten days later, however, severe vomiting recurred, in spite of continued medical treatment. Deterioration in the $\mathrm{CBC}$ and biochemical profile, especially in $\mathrm{PCV}$, were assessed at this point. Given the possibility of a neoplastic disease of the duodenum or pancreas, we decided to perform an exploratory laparotomy, together with parenteral nutrition therapy and blood transfusion via the central vein. Some swelling was found in the pancreatic region (Fig. 2) and this area was biopsied for histological examination. A tumor originating in islet cells was strongly suggested by hematoxylin-eosin (HE) staining. To identify the origin of the tumor cells, immunohistochemical staining was performed. Paraffin-embedded tissue sections at a thickness of a 4-5 $\mu \mathrm{m}$, prepared by standard methods, were stained by the peroxidase-labelled antibody method with anti-gastrin polyclonal rabbit serum (Nichirei Co., Tokyo,

Table 1. Hematological and biochemical findings in a patient dog on first admission

\begin{tabular}{llllll}
\hline $\mathrm{RBC}$ & $536 \times 10^{4} / \mu l$ & $\mathrm{TP}$ & $5.1 \mathrm{~g} / \mathrm{d} l$ & $\mathrm{BUN}$ & $21.5 \mathrm{mg} / \mathrm{d} l$ \\
$\mathrm{Ht}$ & $37.9 \%$ & $\mathrm{Alb}$ & $2.7 \mathrm{~g} / \mathrm{d} l$ & $\mathrm{Cre}$ & $0.52 \mathrm{mg} / \mathrm{d} l$ \\
$\mathrm{Hb}$ & $14.8 \mathrm{~g} / \mathrm{d} l$ & $\mathrm{~A} / \mathrm{G}$ & 1.1 & $\mathrm{Glu}$ & $146 \mathrm{mg} / \mathrm{d} l$ \\
$\mathrm{WBC}$ & $508 \times 10^{2} / \mu l$ & $\mathrm{LDH}$ & $54 \mathrm{IU} / l$ & $\mathrm{TCho}$ & $90 \mathrm{mg} / \mathrm{d} l$ \\
$\mathrm{Band}$ & $30,734 / \mu l$ & $\mathrm{AST}$ & $19 \mathrm{IU} / l$ & $\mathrm{Ca}$ & $7.6 \mathrm{mg} / \mathrm{d} l$ \\
$\mathrm{Seg}$ & $17,526 / \mu l$ & $\mathrm{ALT}$ & $24 \mathrm{IU} / l$ & $\mathrm{P}$ & $3.1 \mathrm{mg} / \mathrm{d} l$ \\
$\mathrm{Lym}$ & $762 / \mu l$ & $\mathrm{ALP}$ & $162 \mathrm{IU} / l$ & $\mathrm{Na}$ & $139 \mathrm{mEq} / l$ \\
Mono & $1,524 / \mu l$ & $\mathrm{GGT}$ & $4.6 \mathrm{IU} / l$ & $\mathrm{~K}$ & $2.8 \mathrm{mEq} / l$ \\
Eos & $254 / \mu l$ & $\mathrm{Amy}$ & $684 \mathrm{IU} / l$ & $\mathrm{Cl}$ & $95 \mathrm{mEq} / l$ \\
Bas & $0 / \mu l$ & $\mathrm{CPK}$ & $43 \mathrm{IU} / l$ & & \\
\hline
\end{tabular}




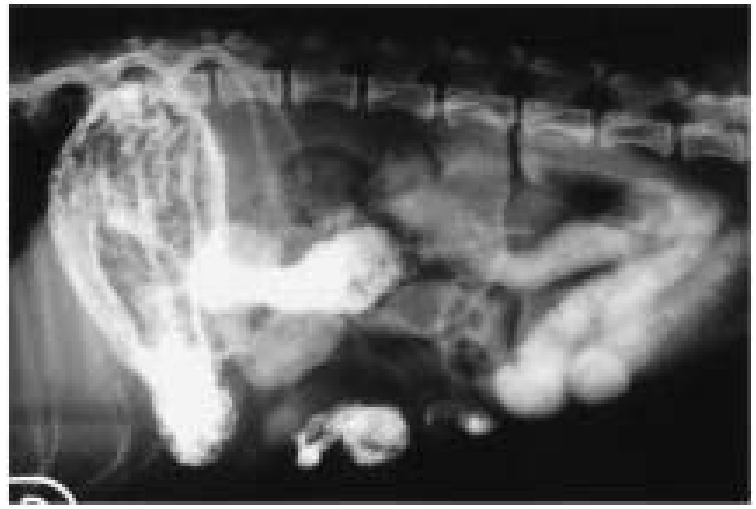

Fig. 1. Contrast radiography. Contrast radiography showed an irregular membrane of the duodenum and a thickened wall throughout the small intestine. No other findings suggesting the presence of a foreign body in the digestive tract or intussusception were obtained.

Japan) as the primary antibody. Peroxidase-conjugated anti-rabbit IgG (Nichirei Co., Tokyo, Japan) was used as the secondary antibody. Specific signals were colored with diaminobenzidine (DAB) (Nichirei Co., Tokyo, Japan). A counterstain for nuclei was performed with Mayer's hematoxylin. Because of the many neoplastic cells that were positively stained (Fig. 3), we concluded that the tumor was a gastrinoma, originating in a gastrin-secreting endocrine cell. Subsequent measurement of the gastrin concentration in the preserved serum demonstrated a high level of gastrin (1266 $\mathrm{pg} / \mathrm{m} l$ vs 10 to $40 \mathrm{pg} / \mathrm{m} l$ for the normal range [4]), supporting the diagnosis based on immunohistochemical examination.

In the original report on the subject, gastrinoma is described as a gastrin-secreting tumor originating in the pancreatic islet cells [16]. Normally, in adults, gastrin is secreted from the duodenum and gastric pylorus, not from the pancreas [13]. Only during the fetal period are gastrinsecreting cells found in the pancreas. They are not seen in the adult pancreas except as a neoplasm such as gastrinoma [6]. The clinical symptoms associated with gastrinoma, such as chronic vomiting, weight loss, gastrointestinal ulceration, and pyloric hypertrophy, characterize its diagnosis. Nevertheless, the most important clinical hallmark of the disease is hypergastrinemia. A high blood gastrin level exceeding $1,000 \mathrm{pg} / \mathrm{m} l$ coupled with a basal acid output exceeding $15 \mathrm{mmol} / \mathrm{hr}$ is considered diagnostic for gastrinoma in humans [3]. When the fasting gastrin level is normal or mildly elevated (100 to $1,000 \mathrm{pg} / \mathrm{ml}$ ), a provocative test, the secretin challenge test, is necessary to diagnose gastrinoma, and rule out other causes of hypergastrinemia including renal failure, liver disease, pernicious anemia, and gastric diseases associated with hypo- or achlorhydria $[8,9$, 12]. If an increase in the gastrin levels of $>200 \mathrm{pg} / \mathrm{ml}$ or a two-fold increase over the basal value is observed within 15 min after a secretin challenge ( 2 to $4 \mathrm{U} / \mathrm{kg}$, I.V.), it is considered positive for gastrinoma in humans [3]. For canines

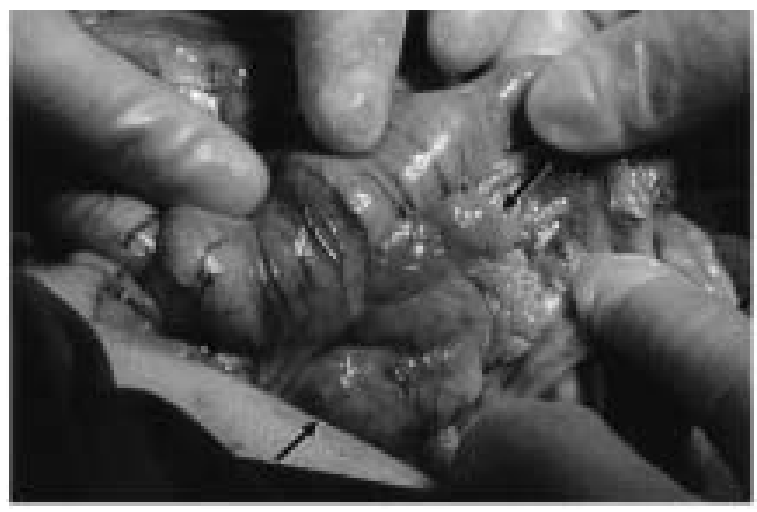

Fig. 2. Photograph of the pancreas at the experimental laparotomy. Regions showing some swelling were found (arrows).

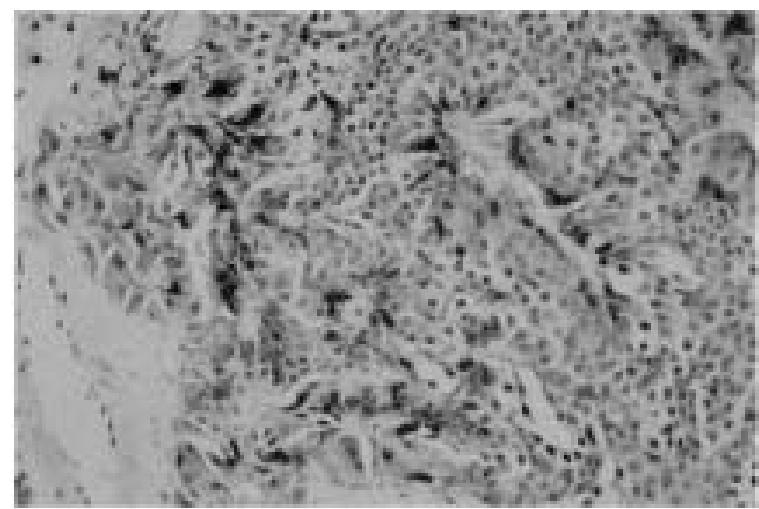

Fig. 3. Immunostaining for gastrin on pancreatic sections. Sections prepared from the biopsied pancreatic tissues were incubated with antigastrin antibody. The specific signals were visualized with DAB. Many neoplastic cells positive for gastrin were found.

with gastrinoma it is reported that gastrin levels rise noticeably elevate within 2 to 5 min after intravenous administration of secretin (2 to 4 unit $/ \mathrm{kg}$ ) [15]. Another diagnostic test, the calcium challenge test, is sometimes used for the diagnosis of gastrinoma. Calcium gluconate $(2 \mathrm{mg} / \mathrm{kg})$ is given intravenousely, and serum samples are collected before and at 15, 30, 60, 90 and 120 min after administration [15]. In humans, a $50 \%$ or greater increase in the gastrin level is diagnostic [11]. In our case the dog's clinical condition worsened following exploratory laparotomy, and the animal died before the provocative tests could be conducted, but an extremely high basal gastrin level was detected.

The primary aim of medical therapy in gastrinoma is to control gastric acid hypersecretion. To this end, $\mathrm{H}_{2}$ histamine antagonists have been used because of their excellent inhibitory effect in controlling acid secretion [1]. Recently, however, omeprazole, a proton pump inhibitor, that covalently binds to $\mathrm{H}^{+}-\mathrm{K}^{+}$-ATPase, has been recommended as the most effective acid inhibitory agent in humans with Zollinger-Ellison syndrome and in dogs with gastrinoma [2, 
7]. Hypergastrinemia stimulates the secretion of gastric acid directly from parietal cells as well as indirectly via histamine release from enterochromaffin-like cells or mast cells around the gastrin-secreting cells. Given these findings, omeprazole would have been efficacious for our case, in which severe vomiting recurred in spite of continuous administration of an $\mathrm{H}_{2}$ receptor antagonist (ranitidine). Although chemotherapy protocols based on single agent or combinations of doxorubicin, 5-flurouracil, and streptozotocin are conducted in humans only when metastasis is demonstrated [10], the effects have not been fully evaluated in dogs or cats with gastrinoma.

An appropriate surgical approach for this disease today is curative resection of the neoplasm for individuals without metastatic disease [6]. In fact, however, the gastrinoma is often very small, and many cases have been reported in which diagnosis of primary gastinoma with no metastasis is difficult in spite of the use of CT or MRI [5]. Therefore, for curative surgery it is critical to diagnose and localize the tumor at an early stage, before metastasis.

In conclusion, gastrinoma should be taken into the differential diagnosis when clinical symptoms include chronic vomiting and marked weight loss. Based on clinical presentation and the results of appropriate tests including provocative tests and immunocytochemical examination of biopsid tissues, the disease is not difficult to diagnose. Early diagnosis and aggressive treatment are necessary to improve the prognosis and survival of patients with gastrinoma.

\section{REFERENCES}

1. Altschul, M., Simpson, K.W., Dykes, N.L., Mauldin, E.A., Reubi, J.C. and Cummings, J.F. 1997. J. Small Anim. Pract.
38: $286-291$.

2. Brooks, D. and Watson, G.L. 1997. J. Vet. Intern. Med. 11: 379-381.

3. Frucht, H., Howard, J.M., Slaff, J.I., Wanlc, S.A., McCarthy, D.M., Maton, P.N., Vinayek, R.,Gardner, J.D. and Jensen, R.T. 1989. Ann. Intern. Med. 111: 713-722.

4. Green R.A. and Gartrell, C.L. 1997. J. Am. Anim. Hosp. Assoc. 33: 524-527.

5. Jensen, R.T. 1996. Baillieres Clin. Gastroenterol. 10: 603643.

6. Konturek, S. J., Konturek, P., Bielanski, W., Lorens, K. et al. 2002. Med. Sci. Monit. 8: 43-59.

7. Maton, N.P., Vinayek, R., Frucht, H., McArthur, A.K. and Miller, S.L. 1989. Gastroenterology 97: 827-836.

8. McGuigan, J.E. and Trudeau, W. L. 1970. New Engl. J. Med. 12: $358-361$.

9. McGuigan, J.E. and Trudeau, W. L. 1973. Gastroenterology 64: $22-25$.

10. Meko, J.B. and Norton, J.A. 1995. Ann. Rev. Med. 46: 395411.

11. Palmer, J.G. and Fiddian-Green, R.G. 1981. pp. 473-494. In: Pancreatic Disease, Diagnosis and Theraphy (Dent, T.L. ed.), Grune \& Sreatton, New York.

12. Schrumpf, E. and Myren, J. 1973. Scand. J. Gastroenterol. 8: $479-482$

13. Strombeek, D.R. and Guilford, W.G. 1990. pp. 90-118. In: Small Animal Gastroentelology, 2nd ed. (Strombeck, D.R. and Guilford, W.G. eds.), Strongate Publishing.

14. Walsh, J.H. 1994. pp. 1-128. In: Physiology of the Gastrointestinal Tract, 3rd ed. (Johnson, L.R. ed.), Raven Press, New York.

15. Zerbe, C.A. 1992. pp. 368-375. In: Current Veterinary Therapy XI, Small Animal Practice (Kirk, R.W. and Bonagura, J.D. eds.), WB Saunders, Phiadelphia.

16. Zollinger, R. M. and Ellison, E.H. 1955. Ann. Surg. 142: 709. 